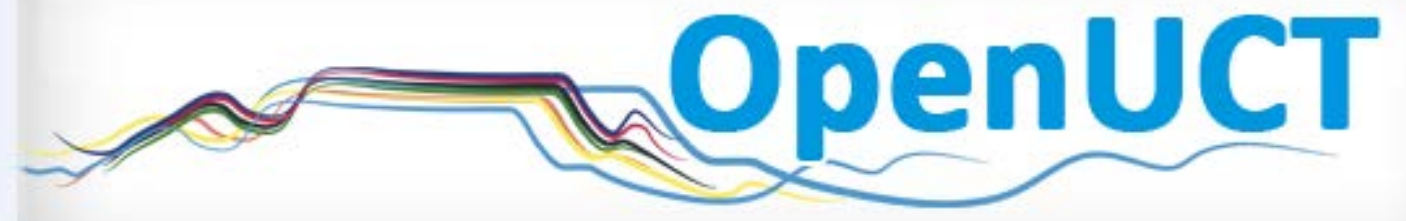

This is the post-print of Kilpert, L. \& Shay, S. 2013. Kindling fires: examining the potential for cumulative learning in a journalism curriculum. Teaching in higher education. 18(1): 40-52. DOI: 10.1080/13562517.2012.678326.

It is made available according to the terms of agreement between the author and the journal, and in accordance with UCT's open access policy available:

http://www.openuct.uct.ac.za/sites/default/files/UCTOpenAccessPolicy.pdf, for the purposes of research, teaching and private study. 


\title{
curriculum
}

\section{Kindling fires: examining the potential for cumulative learning in a Journalism}

\author{
Leigh Kilpert and Suellen Shay
}

Chemical and Life Sciences and Engineering Division, King Abdullah University of Science and Technology, Building 9, Room 3341, Thuwal, nr Jeddah 23955-6900, Saudi Arabia; bCentre for Higher Education Development (CHED), University of Cape Town, Private Bag X3, Rondebosch, Cape Town 7701, South Africa

\begin{abstract}
This study investigated context-dependency of learning as an indicator for students' potential to continue learning after graduation. We used Maton's theoretical concepts of 'cumulative' and 'segmented' learning, and 'semantic gravity', to look for context-independent learning in students' assessments in a Journalism curriculum. We postulated whether the curriculum constrained or enabled cumulative learning. Students' responses to assessments were coded by their degree of context-dependency, or semantic gravity. We found that, firstly, students are overly successful in producing context-dependent answers but struggle to deliver context-independent responses. Secondly, students were not effective when they used higher level knowledge principles without the foundation of lower level ones. Lastly, the marking criteria were encouraging markers to reward context-dependent answers over context-independent ones. This study has implications for educators interested in curriculum design that enables cumulative learning in discipline specific contexts.
\end{abstract}

Keywords: cumulative and segmented learning; context-independent knowledge; semantic gravity; curriculum development; assessment

\section{Introduction}

The mind is not a vessel to be filled but a fire to be kindled.

\section{Plutarch (Ancient Greek Author, 46Á119)}

It is now commonly believed that one of the primary roles of higher education is to prepare graduates for their careers. This concern is often framed as 'lifelong learning' Á the graduate continues to learn independently, beyond the culmination of formal studies, and thus be trainable, employable and productive in society. This focus on lifelong learning is both a South African and an international concern. If higher education aspires to produce lifelong learners, we need a better understanding of the curriculum conditions that enable the development of this kind of learning. This paper explores these conditions in the context of a Journalism qualification offered through a private higher education provider in South Africa. This exploration is inspired by Maton's (2009a) theoretical concepts of 'cumulative' and 'segmented' learning. Cumulative learning means that students are able to use new 
learning to build on previously acquired knowledge or skills. It means that graduates can apply what they have learnt during their studies to unfamiliar workplace situations. In contrast, segmented learning means that students cannot make significant links between the knowledge and skills they have acquired, and new learning does not develop from these. Maton (2009a) argues that the extent to which students engage in cumulative or segmented learning depends on the context-dependency of the knowledge they are given access to, what he terms its 'semantic gravity'. He argues that one of the conditions for cumulative learning is that students must be given access to context-independent knowledge or knowledge with low semantic gravity.

Applying these concepts to the Journalism curriculum, we investigated students' performances on assessment tasks of a news writing module in the Journalism programme. We asked: What evidence of cumulative learning is there in students' performances? We investigated how context-bound the students' responses were and whether this curriculum constrains or enables cumulative learning.

This paper will contextualise the study, provide the theoretical grounding, followed by the operationalisation of this theory into an analytical tool. We then present and discuss the key findings. We will argue that the semantic gravity of the assessments (the context-dependency of the questions, tasks and solutions) affects students' ability to engage in higher order learning which will be crucial to them as lifelong learners. We hope that this argument contributes to current and crucial debates on what constitutes strong vocational curricula, in particular what kinds of knowledge are necessary for graduates to be lifelong learners. Our study deepens the appreciation for the challenges of alignment (Biggs 1996), especially for vocational curricula where the learning outcomes need to meet the demands of both practice and higher education.

\section{Relevance to South Africa's educational context and international interest}

The post-apartheid South African Government has been attempting to deal with the dual challenges of development and democratisation of education. The Education White Paper 3 of 1997 summarises these competing priorities. On the one hand, they claim that higher education must 'address the development needs of society and provide the labour market, in a knowledge-driven and knowledge-dependent society, with the ever-changing high-level competencies and expertise necessary for the growth and prosperity of a modern economy'; on the other, they expect higher education to contribute to the transformation of South African society, as 'part of the broader process of South Africa's political, social and economic transition, which includes political democratisation, economic reconstruction and development, and redistributive social policies aimed at equity' (Department of Education 1997, 1, 3).

One method used to facilitate these changes is a programmes-based and outcomes-based definition of higher education. These changes indicate the State's commitment to curricula which are 'supportive of ... . the needs of the economy' (Moore and Young 2001, 447). The focus of this approach is the trainability and assumed productivity of those receiving an education. There is an emphasis on preparing students for lifelong learning and on education that will lead them into useful vocations. 
These policies problematically assume a smooth transition between academic knowledge and the situated knowledge of the workplace. Some would argue that these policies have created a curriculum crisis (Muller 2008). A number of scholars have critiqued these policy shifts and their curriculum implications. Wheelahan (2007), in her research on competency-based training, argues that vocationally trained students require access to disciplinary knowledge. This is echoed in Clegg's call (2011) that students from historically disadvantaged backgrounds need context-independent knowledge. This poses interesting curriculum challenges. Barnett (2006) in his studies on vocational knowledge and pedagogy notes the difficulty of 'recontextualising' situated knowledge into educational knowledge, of creating curricula that facilitate the transferral of both disciplinary and occupational knowledge. He likens this difficulty to 'constructing a bridge between two unstable land masses' (Barnett 2006, 155).

The Journalism programme and its assessments, the focus of this paper, is an example of a vocation-driven curriculum. This two-year diploma is offered by a private provider and is set on level one of higher education on the South African National Qualification Framework. For their own sustainability, private higher education providers are trying to satisfy the need for vocation-driven qualifications by offering alternatives to the public institutions' more academically oriented degrees or more technologically oriented diplomas. They are responding to the government's call for lifelong learners by providing programmes intended to prepare graduates who, through the content of their studies and required experiential learning, are able to step directly into jobs and be productive. These graduates must also be able to continue to learn while pursuing their careers, using their education as a platform for their development.

\section{Challenges in developing a Journalism curriculum}

Certain features of the field of Journalism pose challenges for its translation into a discipline and a curriculum. Vorster (2009) notes, 'Journalism as a field does not have a generally agreed-upon coherent body of knowledge which makes up the curriculum' (140). Barnett would agree with this Á when describing vocational pedagogy, he explains that it fills a space between subjects and jobs and that 'academic subjects do not map onto jobs in any very straightforward manner' $(2006,145)$. When examining knowledge fields, Muller noticed that 'independent disciplines may converge to form a new field, or region, of knowledge, comprised of clusters of disciplines now come together to focus on a supervening purpose' (2008, 15; italics in original). Thus academic Journalism Á comprised of disciplines such as: media law, politics, economics, sociology, the historical role of the media, language studies and communication studies Á can be described as a region of knowledge that provides the collection of meta-theory for a particular professional practice (Muller 2008). Regions lie 'at the interface between disciplinary knowledge and the field of practice' (Bernstein 2000, 52).

Gamble (2009) would refine this by suggesting that the practice of Journalism belongs to the empirical domain and that it specifically takes the form of principled knowledge. Journalists often claim to work by instinct, which may just be another way of saying that the principles they apply are very deeply entrenched in the procedures they use. Extracting these principles to create a set of rules to use in developing a curriculum is part of the difficulty. Drawing on Muller (2008), recontextualising 
Journalism is trying 'to "pedagogise" what is essentially contextually tacit procedural knowledge' (26).

A Journalism curriculum must therefore make room for the situated knowledge that is related to practical work tasks (Barnett 2006). Barnett (2006) distinguishes between disciplinary knowledge and situated knowledge by explaining that situated knowledge is 'often trapped within its context of application, while disciplinary knowledge generally aspires to some degree of context-independence' (146).

Vocational curricula developers are faced with dual difficulties: extricating slippery tacit and implicit procedural knowledge from the field of practice, while linking it to meta-principles that are embedded in various disciplines. They must design the vocation-related Journalism curriculum to 'face both ways', as Barnett (2006) puts it: towards the practical aspects of the occupation it derives from and the theoretical concepts that explain the underlying processes that influence the occupation.

In the curriculum on which we based our research, we can see an attempt to design 'authentic activities' in this curriculum Á 'experiences that reflect real-world ways of knowing and doing ... [that] allow learners to transfer knowledge from formal education to practice' (Bennett, Harper, and Hedberg 2001,73 ). The purpose of getting students to write articles in various news writing styles is to give them experience of being 'real' journalists. These authentic tasks require students to synthesise knowledge from a number of disciplines, as well as procedures from the field of practice. These different sets of knowledge do not necessarily sit comfortably together. To make sense of the different parts of this curriculum, the student may need to refer back to the student manual, the structure and context from which he or she acquired the knowledge, which means that the curriculum could be strongly context-bound and have a strong semantic gravity. But the fact that the assessments are intended to be 'authentic' and encourage the use of context-independent thinking points to an attempt to weaken the semantic gravity, which leads us to wonder exactly which way this curriculum is facing. In other words, the students get pulled in opposite directions Á on one hand, towards the context-independent assessments, and on the other hand, towards the context-bound content of the rest of the curriculum. These factors create a 'contextual' tension and students could be caught in the middle of it.

\section{Theoretical framework}

Maton (2009a) framed the issue of lifelong learning by using what he calls 'cumulative' and 'segmented' forms of learning. Maton noted how policies dictate that curriculum design must encourage cumulative learning to create graduates who are able to adapt to the requirements of the rapidly changing working world. To further explore this, he examined a study conducted by Bennett (2002) for evidence that the selected curricula actually did what they claimed, that is, enable cumulative learning. Our study emulated Maton's investigations (2009a) and reflected on his findings from a South African perspective.

Bernstein (2000) distinguishes two different types of knowledge structures: horizontal and hierarchical. This metaphorical language indicates something of the way in which these kinds of knowledge develop Á the one by integration and subsumption, the other by segmentally adding on. Maton (2009a) extends Bernstein's concepts to describe different kinds of curricula. A hierarchical 
curriculum structure is one in which the information builds on the previous year's or module's learning 'through integration and subsumption' of knowledge (45). A horizontal curriculum structure increases knowledge through 'segmental aggregation' (Maton (2009a, 45). Maton further develops his concepts to describe the way students learn. If they develop their understanding by using their previous learning as a foundation, by exercising this knowledge in unfamiliar contexts, this is cumulative learning (Maton 2009a). If, on the other hand, they develop their understanding by acquiring knowledge in discrete chunks and are unable to transfer this learning because it is context-specific, then this is segmented learning (Maton 2009a). Maton relates these two ways of learning to the aforementioned hierarchical and horizontal curriculum structures, and concludes that the former might assist a student's cumulative learning, since it is designed to build on accumulated knowledge, but that the latter might hinder it.

According to Maton (2009a), one of the key conditions for the cumulative learning is the context-dependence or context-independence of educational knowledge, which he refers to as semantic gravity Á 'the degree to which meaning is dependent on its context' (46). The stronger the dependency on context for meaning, the stronger the semantic gravity. Conversely, the weaker the attachment to context, the weaker the semantic gravity. This means that cumulative learning, with its emphasis on context-liberated information and understanding, has a weaker semantic gravity than segmented learning, which is context-bound. Maton asserts that 'cumulative learning depends on weaker semantic gravity and segmented learning is characterised by stronger semantic gravity, constraining the transfer of meaning between contexts' $(2009 a, 46)$. This statement leads to his hypothesis that 'one condition for building knowledge or understanding over time may be weaker semantic gravity' (Maton 2009a, 46).

Maton's (2009a) investigation of Bennett's (2002) study revealed that the students' responses to their assessments reflect their difficulty in separating from the context of their studies and show their experience of segmented learning. He suggests that this is because of 'a mismatch between [the] aim of enabling students to acquire higher-order principles of knowledge and their means, which focus on knowers' dispositions rather than explicitly articulating these principles of knowledge' (Maton's 2009a, 44).

\section{Methodology}

This study examined whether there is evidence of cumulative learning in the students' responses to assessments, that is, whether the responses are context-dependent (having strong semantic gravity) or context-independent (having weak semantic gravity). If the responses show that learning is stuck in the context from which it came, then the students will have experienced segmented learning, and thus will be unable to make effective use of their learning in novel contexts.

The curriculum that was the focus of this study was Newswriting 2, a second year module of a Journalism diploma. Newswriting 2 is provided as a series of lectures (three hours a week) over one semester (about 16 weeks). The students are given a manual that contains all assessable material. The institution gives the lecturer a manual with content and suggestions on how to teach the course. The institution develops all assessments. This curriculum had two tests, two assignments and one 
final exam. There were 5 questions in Test 1, 7 questions in Test 2, 2 questions in Assignment 1, 3 questions in Assignment 2, and 20 questions in the exam, so 37 questions were examined in total. There were 29 Journalism students in this course. Two students left the programme and submitted no assessments for this module, leaving 27 who submitted all or most of the assessments. A total of 129 assessment scripts were collected for coding and analysis. Neither of the authors was involved with teaching or developing material or assessments for this curriculum. One author was an academic administrator in the institution being researched and she conducted the research for the purposes of postgraduate studies. The other author supervised the research.

The analysis was two staged: firstly, the assessment tasks, and secondly, the students' responses to the assessments. For the assessment tasks, we examined both the questions and the model answers and deliberated which 'knowledge principle' seemed to be expected in the students' responses and what reference to context (what level of semantic gravity) each question seemed to require. For the students' responses, we examined which 'knowledge principle' was being used.

By 'knowledge principle', we mean the categories of knowledge developed for this research project's research tool (Figure 1). The concept of 'knowledge principle' can be defined as the level of semantic gravity in either the assessment task or the student's assessment answer. This concept is a means to measure semantic gravity.

The knowledge principle reflects the 'what' and 'how' of the student's learning with regards to that question, and how context-dependent the student's answers are. Questions that only expected students to recall facts from the manual would be operating with strong semantic gravity, whereas questions that expected application to an unfamiliar context would be operating with a 'lighter' semantic gravity. Briefly described, the tests had more instances of questions with strong semantic gravity (requiring verbatim recall from the student manual and less comprehension) and the assignments tended to include tasks with weaker semantic gravity (requiring practical and creative responses that were less dependent on the student manual). For the final exam, half of the questions had strong or very strong semantic gravity, a quarter showed weakening semantic gravity and only one had very weak semantic gravity (little reference to the classroom context). Overall the assessments provided evidence of strong semantic gravity in this curriculum.

The students' responses to questions in the assessments were broken up into 'units of meaning', which Maton describes as 'passages conveying a single coherent meaning' (Maton 2009a, 48). For this data, this meant reviewing the student's answer as a whole. In some cases, the student's answer was simply one word, or a bulleted list of words or phrases; on other cases, the student's whole article was taken into consideration. Each of the 961 'units of meaning' was coded by one knowledge principle or a sequence of knowledge principles, according to the analytical tool we developed from Maton's language of description for semantic gravity (2009a). Figure 1 illustrates our analytical tool, adapted from Maton (2009a, 49).

Originally, Maton's language of description (2009a, adapted from Bennett 2002) consisted of six categories of knowledge principle: Reproductive description, Summarising description, Interpretation, Judgement, Generalisation and Abstraction, listed in order, from those with the strongest semantic gravity (most reliant on classroom context for meaning) to those with the weakest (least reliant on classroom context for meaning). 


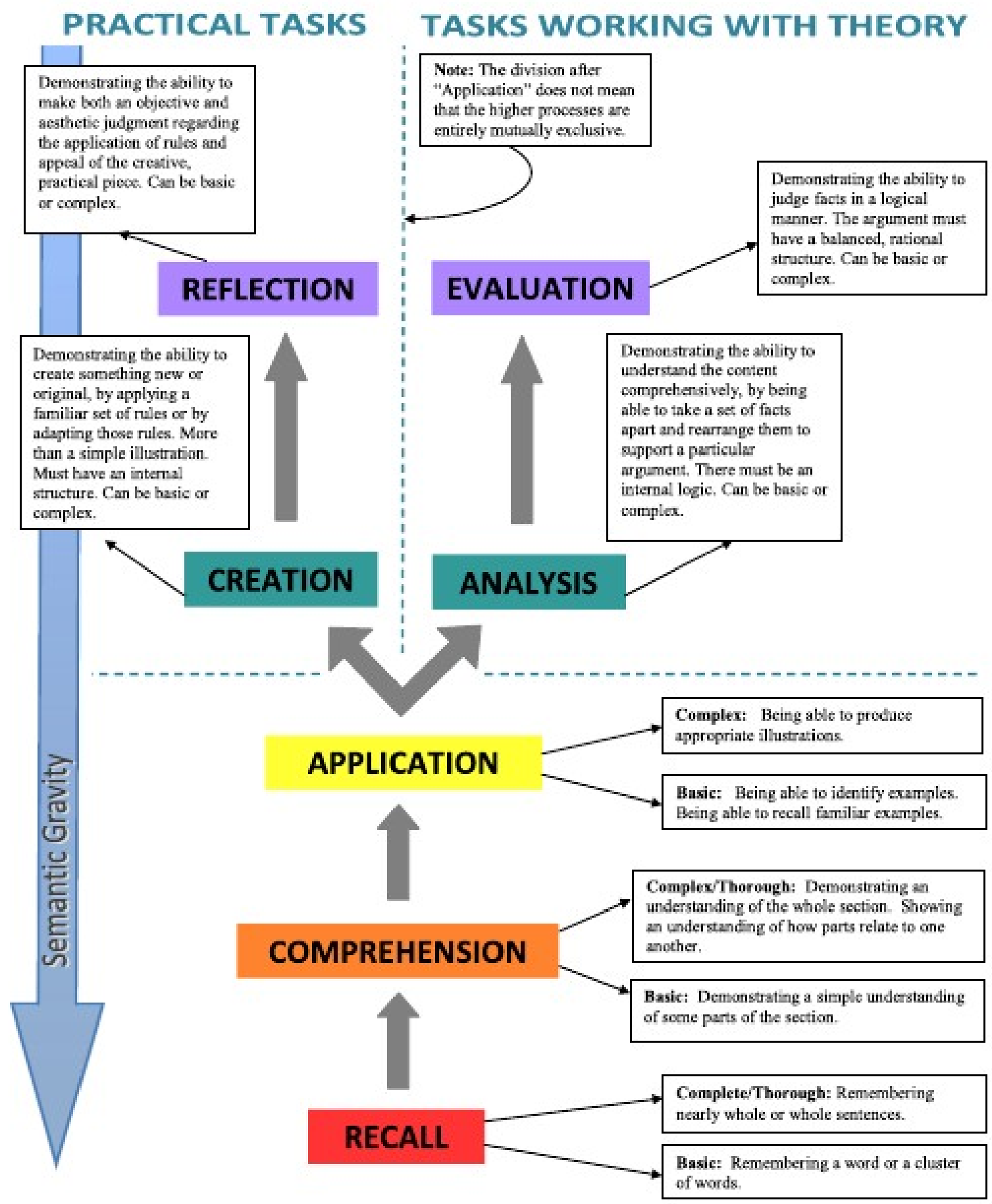

\section{KNOWLEDGE PRINCIPLES}

Figure 1. Diagram of the analytical tool used to measure semantic gravity.

A review of the assessment questions, and a few of the students' responses, revealed that the six categories that Maton drew from Bennett's research would be inadequate for describing the forms of learning and thinking in the Journalism students' responses. The reason for this decision was the different nature of the assessment tasks that were examined in Bennett's research. Bennett's research (2002) focused on postgraduate students' instructional design work and their assessment tasks required answers to increasingly complex questions, based on a set of unstructured data from 
interviews. The assessment tasks behind our research data involve more limited answers with less demand for higher level knowledge principles, plus some questions that require students to produce original writing. We needed to re-create categories that would reflect the knowledge principles that the Journalism students were using and at the same time maintain the continuum for measuring semantic gravity.

We modelled our analytical tool on Bloom's Taxonomy of Educational Objectives (1956, revised by Krathwohl 2002). This taxonomy provided us with a new set of categories: Remember, Understand, Apply, Analyse, Evaluate and Create. Through the iterative process of using this tool, we discovered that Bloom's categories did not do justice to the practical tasks that students were required to perform. For example, a number of assessment tasks asked them to write articles for newspapers or magazines. If these tasks and the students' responses were classified under Bloom's categories, it might be difficult to decide whether they fell under 'Apply Á Carrying out or using a procedure in a given situation' or 'Create Á Putting elements together to form a novel, coherent whole or make an original product' (Krathwohl 2002, 215). Other tasks asked students to do research, analyse content and write well-structured essays, which we considered had aspects of innovation and judgement. For the purposes of this research, where we were trying to rebuild a rising continuum to measure semantic gravity, we found it inappropriate to rank 'Create' as the highest form, while relegating analysis and evaluation to lower levels. It was at this point that we chose to split the taxonomy after 'Apply' to create two divisions Á one for coding practical tasks and one for coding tasks that involved theory. It is important note that these two principles, creating and applying, are not mutually exclusive. There is an element of creation in analysis (for example, designing a structure for the argument), just as there is an element of analysis in creation (for example, deciding what to include or omit). Similarly, Reflect and Evaluate are cognitive processes that have elements in common, but Reflect leans more towards aesthetic judgement and personal appeal, whereas Evaluate depends more on logic and rational debate. This split gave us seven categories, ranked from stronger to weaker semantic gravity.

Our coding was intuitive, based on personal judgement. The assessment questions, model answers and students' responses were coded by one researcher and this coding was reviewed and cross-checked by the other researcher. We examined how closely the student's response matched what the question seemed to expect. Once we had finished coding the student responses, we examined the coding for patterns. This was not as straightforward as grouping the units of meaning according to the seven categories of knowledge principles and counting the number of instances: it was more iterative and interpretive. We examined the trends in the coding to see if one knowledge principle was more evident than others. We also looked for anomalies in the students' responses; not necessarily incorrect answers, but whether students were using higher or lower levels of knowledge principles than the question seemed to expect. These observations provided the basis for our analysis.

\section{Analysis of results}

Three salient observations were drawn from the analysis of the data. Firstly, there appears to be a gap between practising lower level knowledge principles, with strong semantic gravity, and practising higher level knowledge principles, with weaker semantic gravity. Students try to release themselves from the 


\section{L. Kilpert and S. Shay}

context of the students' manual when limited by questions that required lower level knowledge principles, but struggle to be truly successful in using higher level knowledge principles. These two kinds of behaviour could be described as 'overreaching the target' and 'falling short of the target'. We suggest the following reasons for these behaviours.

In terms of 'overreaching the target', students repeatedly 'over-answered' the questions. This indicated that they were unclear as to what was expected of them in assessments. They used whichever knowledge principles were available in their toolbox of abilities. As example, see the question, model answer and student's answer below:

\footnotetext{
Exam question: List the five (5) key people with whom the court reporter needs to develop contacts within the legal system.
}

Model answer: Court reporters have to develop contacts with Á lawyers (1), judges (1), prosecutors (1), translators (1), the clerk of the court (1).

Student's answer: attorneys or lawyers, the South African Police Service, magistrate or judge, state prosecutor, witnesses.

The student's answer was coded for Recall with some evidence of comprehension.

This response showed that the student remembered most of the items as per the marking criteria's solution, but where she could not remember, her answer tried to show that she understood what was expected of her. She knows that witnesses and the police are part of the legal system and therefore might be considered worthwhile contacts for a journalist. She hopes that by mentioning them she will be awarded more points. However, she was not rewarded for this understanding of the legal system, but merely for the three correctly identified items. If a student used Comprehend to answer a simple Recall question, then this was evidence of use of a higher form of knowledge principle, and thus a weaker form of semantic gravity than what was required. By pushing beyond the level that is expected of them, these higher education students seem to be straining against the boundaries that hold them. However, in many cases like the one above, students were awarded marks primarily for lower level knowledge principles, like reproducing a bullet-point list, rather than higher level knowledge principles. Those who combined these knowledge principles did so either to supplement their answers to ensure they received as many marks as possible, or because they could not remember the exact wording of the answers but wanted to explain that they understood them. This observation shows that what is being expected and rewarded is mostly the facts from the students' manual and not the students' understanding of the facts (Maton 2009a, 2009b).

'Falling short of the target' was evident when students were asked to produce creative writing. As example, see the question, model answer and student's answer below:

Exam question: Write an Intro only using the Gonzo style of new journalism Á the subject is your view on one of the following: Farewell to George W. Bush; Reality TV Shows; Local Music. 
Model answer: (All answers will differ, markers need to look for an understanding of Gonzo style in the paragraphs, and award five marks for full portrayal of understanding.) Gonzo is defined in the New World Dictionary in 1979 as 'bizarre, unrestrained, extravagant, specifically designating a style of personal journalism so characterised'. The Intro must therefore be Gonzo. A simple hard-hitting statement is not enough. It must have that Gonzo flair to it.

Student's answer: Reality TV shows are a complete waste of time. Involving people in other people's life and that being entertainment? How do people view reality shows how do you think is helping people. Reality shows have been a great part of our daily life's and they have made different impact on people whether good or bad (sic).

The student's answer was coded as creative, but the style was applied very basically. This student has created a piece of writing, but she did not produce the Gonzo style with the necessary 'flair', nor did she follow instructions and produce a competent introduction to an article. Some students were able to use the higher knowledge principles in a basic sense, by building up from lower knowledge principles layered beneath them, but some struggled to produce complex creations Á ones that have a logical structure and are also original and appealing.

Secondly, we noticed that some students' responses 'skipped' a knowledge principle and simply used a higher order one. As example, see the question, model answer and student's answer below:

Exam question: Dave Hedley, in his advice on using the building blocks of powerful news writing, suggests that a writer should 'be an original witness to a moving event'. What does he mean?

Model answer: Be an original witness to a moving event Á Take your story live by carefully writing all that you observed (1), drawing on all senses (1). Dispassionate summary (1) may lead readers to the perimeter of a story (1), but they won't experience the story unless you take them there (1).

Student's answer: This means that the writer should take ideas and inspiration from his own life and look at real life events and report on them. In a journalist's life, they are exposed to all different real events and with ultimate credibility, they can come up with true stories that have a lot of impact and will make very interesting stories.

This is a partially correct summary of the marking criteria's solution that shows that the student had some understanding of what was expected, but did not reproduce the exact points. In other words, the student used a higher knowledge principle than was required, but did not use the lower knowledge principle to substantiate this understanding with facts. This type of response was successful when the student's explanation approximated the correct answer. If the student was guessing, he or she was unlikely to receive marks for that question, despite using a higher level knowledge principle. The research tool used for measuring semantic gravity represents both a continuum and a hierarchy of knowledge principles. To be effective, the learning reflected by knowledge principles cannot be used in a segmented fashion, but must be used cumulatively. What we can see here is that higher order knowledge principles are not sufficient in themselves; to be meaningful, they must contain a foundation of lower order knowledge principles. 
This observation also showed that cumulative learning is never free of context. No matter how adept at writing or persuasive a student is, part of the answer has to be 'right'. A student's response will be meaningless without some reference to the consensus of information as defined by that region of knowledge.

Thirdly, we discovered that although the assessments seemed to offer the students opportunities to practice higher level knowledge principles, the assessment marking criteria were constraining the marker by forcing her to reward lower level knowledge principles over the higher level ones. As example, see the question, model answer and student's answer below:

Exam question: Briefly discuss sensationalism as a pitfall faced by health, science and education reporters.

Model answer: Reporters in all these beats must guard against a tendency to over-dramatise or sensationalise issues (1). Not only is this irresponsible, but educationists, scientists, and the medical fraternity are highly sensitive to the injudicious use of emotive terms and language (1) and you could easily do more harm than good (1). This is yet another reason why extensive subject knowledge is so important Á if you really know your subject, you can communicate it with power and in a compelling, intelligible and meaningful way, without resorting to gee-whiz journalism (1). Be careful of cliches' such as 'breakthrough', 'pioneering', 'unprecedented', 'sensational', 'shocking' and the usual array (1).

Student's answer: Sensationalism and dramatisation in this beat could some serious to the reporters and publications reputation. Remember medical experts, educationalist and scientist also read this reports so you have to be very carefull with your reportage.Sensationalism could also cause unnecessary panic for people, especially the health beat. For example, when a reporter exagerates or dramatise a certain virus or break-out of a certain virus, people will stress and panic unnecessary about it, than it is not even that bad (sic).

There were five marks allocated for this question and the answer received three. The student has shown some degree of comprehension and even attempted to apply his knowledge by producing examples. However, because his answer does not match the 'facts' as they appear in the model answer, the evidence of his higher level knowledge principles was not rewarded.

A curriculum and its assessments may be well designed to enable cumulative learning, but unless this form of learning is seen to be valued through results and feedback, students will hesitate to use the higher level knowledge principles that provide evidence of cumulative learning.

\section{Conclusion}

This research investigated what evidence of cumulative learning there was in students' responses to assessments. This was achieved by examining the level of context-dependency of the responses. Context-dependency was measured by ascribing a code that indicated a particular 'weight' of semantic gravity: strong semantic gravity revealed a strong context-dependency and weak semantic gravity a weaker one. This research accepts Maton's premise that the ability to abstract information from the original context indicates that students will be able to apply what they have learnt in 
unfamiliar situations post-graduation. This ability would mean that they had experienced cumulative learning.

We established that cumulative learning is present, but that this learning is restricted and so cannot develop to its full potential during the students' studies. This limitation is the result of a gap between the students' efforts to answer assessment questions that require context-dependent responses and those that require students to reach beyond the classroom. Students' cumulative learning is constrained by their attempts to use higher level knowledge principles before having mastered the lower level ones. We showed that students needed to assimilate all levels of knowledge principles properly in order to experience cumulative learning. The curriculum may require further scaffolding between the lower and the higher knowledge principles, perhaps in the form of different assessment tasks and questions, as the current assessments are promoting this gap in understanding. Essentially, it is offering a segmented curriculum while expecting the students to learn cumulatively. We recommended that this Journalism curriculum incorporate further opportunities to practise mid-range knowledge principles to help solidify the students' abilities before moving onto higher level, more context-independent tasks. This might help alleviate the contextual tension present in the curriculum and aid further cumulative learning. Our findings also indicated that to be able to perform effectively in the higher level practical tasks, students must have thoroughly assimilated the underlying theoretical knowledge base (Gamble 2009; Wheelahan 2007). It seems that for cumulative learning to be comprehensive, the underpinning knowledge base has to be wholly integrated and absorbed. Our final conclusion was that students were also limited by not being rewarded for using context-independent learning. We surmised that cumulative learning would be further enabled in this curriculum if markers were given more freedom to reward thinking and skills that are beyond the context of the students' studies, and not so trapped by the notion of 'correct' answers as dictated by the marking criteria. The procedures set up to standardise this curriculum, and ensure that it complies with strict education policies, appeared to be limiting the institution's ability to reward higher level knowledge principles in students' work. A compromise needs to be reached between the benefits of standards and the pitfalls of standardisation.

The practical implication of our research is for educators who are interested in ensuring that their graduates are able to continue learning and developing their skills. Those who are developing curricula need to have a better understanding of the form of knowledge of the discipline that they are converting into educational tools. This requires an in-depth meta-examination of the vocation or the region of knowledge that results in the organising logic of the curriculum. This opportunity, and many others, was beyond the scope of this research but offer promising avenues for further research into cumulative learning and its relationship to professional disciplines in general. 


\section{References}

Barnett, M. 2006. Vocational knowledge and vocational pedagogy. In Knowledge, curriculum and qualifications for South African further education, ed. M. Young and J. Gamble, 143 Á57. Cape Town: HSRC Press.

Bennett, S. 2002. Learning about design in context: An investigation of learners' interpretations and use of real life cases within a constructivist learning environment created to support authentic design activities. PhD diss., University of Wollongong.

Bennett, S., B. Harper, and J. Hedberg. 2001. Designing real-life cases to support authentic design activities. Australian Journal of Educational Technology 18, no. 1: 1Á12.

Bernstein, B. 2000. Pedagogy, symbolic control and identity: Theory, research, critique, rev. ed. New York \& London: Rowman \& Littlefield.

Biggs, J. 1996. Enhancing teaching through constructive alignment. Higher Education 32, no. 3: 347 Á64.

Bloom, B.S., ed., 1956. Taxonomy of educational objectives: Cognitive domain. New York: David McKay.

Clegg, S. 2011. Cultural capital and agency: Connecting critique and curriculum in higher education. British Journal of Sociology of Education 32, no. 1: 93Á108.

Department of Education. 1997. Education white paper 3: A programme for the transformation of higher education. Pretoria: Government Gazette No. 18207.

Gamble, J. 2009. The relation between knowledge and practice in curriculum and assessment. Concept paper commissioned by Umalusi (Council for Quality Assurance in General and Further Education and Training).

Krathwohl, D. 2002. A revision of Bloom's Taxonomy: An overview. Theory into Practice 41, no. 4: $212 A ́ 9$.

Maton, K. 2009a. Cumulative and segmented learning: Exploring the role of curriculum structures in knowledge-building. British Journal of Sociology of Education 30, no. 1: 43Á57.

Maton, K. 2009b. Analyzing knowledge claims: Languages of legitimation. In Social realism, knowledge and the sociology of education: Coalitions of the mind, ed. K. Maton and R. Moore, 35Á59. London: Continuum.

Moore, R., and M. Young. 2001. Knowledge and the curriculum in the sociology of education: Towards a reconceptualisation. British Journal of Sociology of Education 22, no. 4: 445Á61.

Muller, J. 2008. Forms of knowledge and curriculum coherence. Paper presented at ESRC Seminar Series Á Seminar 2: Epistemology and the Curriculum, June 26Á27, in University of Bath, UK.

Vorster, J. 2009. A social realist analysis of collaborative curriculum development processes in an academic department at a South African university. PhD diss., Rhodes University. 